\title{
IDENTIFIKASI POTENSI DAYA TARIK EKOWISATA AIR TERJUN SEBUAK KECAMATAN NANGA TAYAP KABUPATEN KETAPANG PROVINSI KALIMANTAN BARAT
}

\author{
(Identification Of The Potential Of Sebuak Waterfall As An Ecotourism Attraction In Nanga \\ Tayap Ketapang Regency West Kalimantan)
}

\author{
Liyan Adethiya, Erianto, Hari Prayogo \\ Fakultas Kehutanan Universitas Tanjungpura Jalan Imam Bonjol Pontianak 78124 \\ E-mail: liyan.adethiya95@gmail.com
}

\begin{abstract}
Ketapang Regency has many tourism potentials in both its diversity of resources and its nature's beauty. Many of the tourism potentials are not widely known, one of which is Sebuak waterfall in Nanga Tayap Sub-District. The purpose of this study is to obtain data on potential attraction in Sebuak Waterfall for ecotourism in Nanga Tayap Sub-District, Ketapang Regency. The study uses survey method, while the data collection techniques are direct oservation and interviews. The respondents are determined byusing purposive sampling and are chosen from the leaders of Sebuak Village, Nanga Tayap, and from the visitor of the waterfall. The result of this study indicates the tourism attraction with data of biological potential, such as various kinds of flora like mosses, pine trees, rattan, Nepenthes (tropical pitcher plants), mushrooms, and various kinds of fauna such as clown fish, shrimp, birds, butterflies, snakes, grasshoppers, non-biological potential namely the waterfall, views from above and from above and from below the waterfall, water condition in the waterfall it self and the next one is the culture around Sebuak Waterfall. Activities that can be done at Sebuak Waterfall are fishing, tracking, swimming, camping, and education. The results of the identification of the potential elements supporting eco-tourism such as its natural beauty in the form of recretional activities, air cleanliness, security, convenience, accessibility, infrastructure and accommodation of identified criteria, it can be concluded that Sebuak Waterfall is quite good and potential to be a naturetourism destination, because it can be seen from its natural beauty and the convenience of being around Sebuak Waterfall, but there are still many aspects of tourism that must be addressed, such as accessibility, accommodation, facilities and social economic conditions of the local community, so that Sebuak Waterfall can be a nature tourism attractions.
\end{abstract}

Keywords: Ketapang, Nanga Tayap Village, Tourism Potential, Sebuak Waterfall.

\section{PENDAHULUAN}

Ekowisata muncul sebagai salah satu alternatif solusi peningkatan apresiasi masyarakat terhadap alam di tengah lajunya peningkatan deforestasi. Pembangunan industri ekowisata sejalan dengan semangat menggali dan melestarikan potensi sumber daya alam. Selama ini potensi sumber daya alam masih terbatas pada hasil hutan kayu dan non kayu yang bersifat nyata (tangible), padahal sebenarnya sumber daya alam yang tidak nyata (intangible), juga merupakan potensi yang harus dipertimbangkan sebagai penanaman modal yang menarik. Ekowisata merupakan salah satu fungsi tidak nyata yang dapat memberikan 
manfaat ekonomi sebagai salah satu sumber Pendapatan Asli Daerah (PAD).

Ekowisata menurut Fandelli (2000) dalam Fahrian et. al(2015) adalah suatu bentuk perjalanan wisata ke area alami yang dilakukan dengan tujuan mengkoservasi lingkungan dan melestarikan kehidupan dan kesejahteraan penduduk setempat. Tujuannya selain untuk menikmati keindahan alam juga melibatkan unsur-unsur pendidikan, pemahaman dan dukungan terhadap usahausaha konservasi alam dan peningkatan pendapatan masyarakat setempat (Hakim, 2004).

Kawasan wisata alam Air Terjun Sebuak belum banyak diketahui oleh masyarakat daerah maupun luar daerah serta sarana dan prasarana yang belum disediakan seperti penginapan, perbaikan jalan utama dan jalan masuk menuju tempat wisata, belum adanya plang nama objek wisata dan gerbang selamat datang, tetapi sudah ada beberapa pengunjung yang berkemah disekitar lokasi tersebut untuk sekedar beristarahat ataupun untuk masyarakat yang ingin mengenal lebih banyak tentang objek wisata tersebut. Hingga saat ini belum ada instansi terkait yang berminat untuk mengelola dan membangun tempat tersebut agar memberikan kenyamanan kepada pengunjung yang datang, sehingga diperlukan kajian berupa data potensi yang terdapat di daerah tersebut agar dapat disajikan secara khusus mengenai aspekaspek kepariwisataan yang terdapat di daerah tersebut, maka penelitian ini dilakukan dengan mengidentifikasi seberapa besar potensi daya tarik Air
Terjun Sebuak untuk dijadikan sebagai objek wisata.

Pengelolaan suatu kawasan sebagai daerah wisata sangat ditentukan oleh objekobjek rekreasi yang ada didalamnya, oleh karena itu potensi daya tarik Air Terjun Sebuak ini perlu diketahui, hasil identifikasi potensi daya tarik diharapkan menjadi bahan masukan dan pertimbangan dalam upaya mengelola dan pengembangan pada kawasan tersebut serta untuk mempublikasikan atau mempromosikan kepada masyarakat, pemerintah atau pihak terkait lainnya di lokasi ini.Tujuan penelitian ini adalah untuk memperoleh data potensi daya tarik yang terdapat di kawasan Air Terjun Sebuak untuk wisata alam di Kecamatan Nanga Tayap Kabupaten Ketapang.

\section{METODE PENELITIAN}

Penelitian ini dilakukan di Kecamatan Nanga Tayap Kabupaten Ketapang Provinsi Kalimantan Barat dengan waktu penelitian selama 4 minggu mulai dari 18 september - 18 oktober 2018. Metode yang digunakan dengan metode survey dengan teknik pengambilann data dengan observasi langsung dan wawancara, wawancara dilakukan kepada kepala desa, tokoh masyarakat dan pengunjung. Pemilihan responden ini dilakukan dengan menggunakan teknik purposive sampling yaitu teknik untuk menentukan sampel penelitian dengan beberapa pertimbangan tertentu yang bertujuan agar data yang diperoleh nantinya bisa lebih representatif (Sugiyono, 2010). Alat-alat yang digunakan dalam penelitian ini adalah GPS, kamera, binokuler, kuisoner dan objek yang diteliti adalah Air Terjun Sebuak dan 
data-data yang dikumpulkan data primer yang meliputi potensi wisata yang ada di Air Terjun Sebuak dan data sekunder yang meliputi keadaan umum lokasi penelitian.

\section{Analisa Data}

Analisa data yang digunakan dalam penelitian ini metode deskriptif kualitatif yaitu metode meneliti status sekelompok orang, suatu objek, suatu kondisi, suatu sistem pemikiran, atau suatu kelas peristiwa pada masa sekarang.Tujuan dari penelitian deskriptif ini adalah membuat deskripsi, gambaran atau lukisan secara sistematik, faktual dan akurat mengenai fakta-fakta, sifat-sifat serta hubungan antara fenomena yang diselidiki dan bukan angka. Data yang dianalisis adalah data dan informasi yang telah dikumpulkan dari pengamatan lapangan dan data sekunder mengenai kondisi.

\section{HASIL DAN PEMBAHASAN}

\section{Potensi Hayati}

a. Tumbuhan Lumut Di Bebatuan

Tumbuhan lumut merupakan tumbuhan yang tumbuh di suatu tempat sebelum tumbuhan yang lain mampu tumbuh. Ini terjadi karena tumbuhan lumut merupakan tumbuhan pioner yang membentuk koloni dan dapat menjangkau area yang luas. Jenis lumut yang terdapat di Air Terjun ini adalah Hylocomium spendens, dan Leucobryum glaucum, lumut tersebut memberikan keunikan serta warna, sehingga batuan tersebut menjadi salah satu unsur yang memiliki nilai untuk potensi daya tarik di lokasi Air Terjun Sebuak.

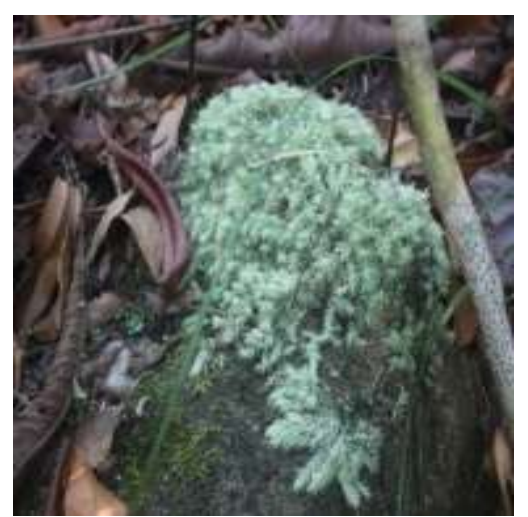

Gambar 1. Lumut Yang Ada Di Bebatuan (Mosses On The Rocks)

b. Pohon

Pepohonan yang ada di Air Terjun Sebuak menambah keindahan karena warna batang pohon yang menarik yaitu bewarna merah, kulit pohon yang bisa mengelupas yang mendominasi di hampir seluruh area Air Terjun Sebuak, jenis pohon ini batangnya seperti pohon jambuan-jambuan ada juga seperti pohon palem, cemara, pohon jenis emkaliptus, dan masih banyak juga tanaman-tanaman lain yang ada di kawasan Air terjun Sebuak. 

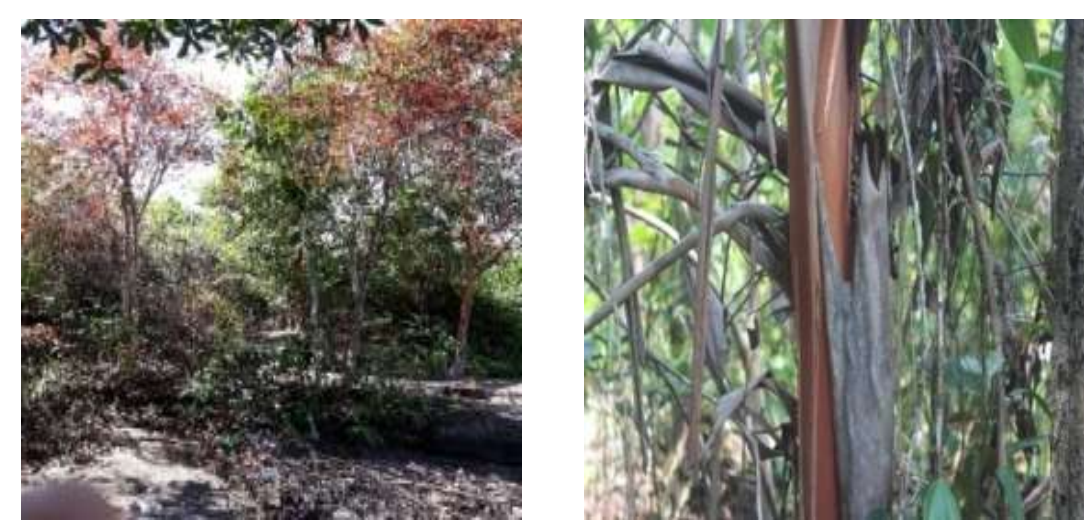

Gambar 2. Pepohonan Yang Mendominasi Di kawasan Air Terjun (Trees Dominating In The Waterfall Area)

c. Kantong Semar (Nepenthes)

Kantong semar adalah tanaman karnivora yang memakan serangga, ulat, dan anak katak. Tanaman ini hidup sebagai tanaman karnivora karena hidup di daerah yang minim unsur nitrat dab fosfat. Sebagai karnivoratumbuhan ini mempunyai alat perangkap serangga berupa kantung atau periuk, yang merupakan perubahan bentuk dari ujung daun. Kantong semar yang ada di kawasan air terjun cukup mendominasi area karena tanaman kantong semar sngat mudah hidup di kawasan ini.

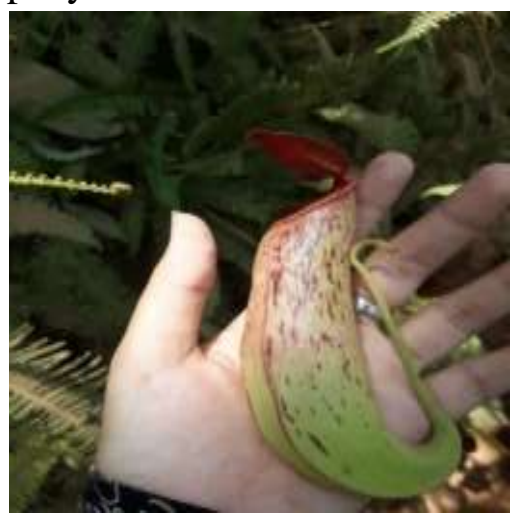

Gambar 3. Tumbuhan Kantong Semar (Nepenthes (tropical pitcher plants))

\section{d. Jamur (Fungi) Makrokopis}

Jamur atau disebut juga cendawan merupakan tumbuhan yang tidak mempunyai klorofil sehingga bersifat heteretrof. Jamur dapat di bedakan menjadi dua tipe yaitu uniseluler dan multiseluler, tubuhnya terdiri dari benang-benang yang disebut hifa. Jamur yang ada di Air Terjun Sebuak cukup bervariasi jenisnya ada jamur jenis Lingzhi dan jamur Ganoderma. a. Udang (Caridea)
Udang adalah binatang yang hidup di perairan, khususnya sungai, laut, dan danau. Udang dapat ditemukan di hampir semua genangan air yang berukuran besar baik air tawar, air payau, maupun air asin pada kedalaman bervariasi dari dekat permukaan hingga beberapa ribu meter di bawah permukaan. Udang yang ada di Air Terjun Sebuak cukup banyak dan dapat di tangkap dengan tangan kita sendiri jenis udang yang ada di air terjun yaitu 
kebanyakan jenis Macrobrachium

acanthurus.

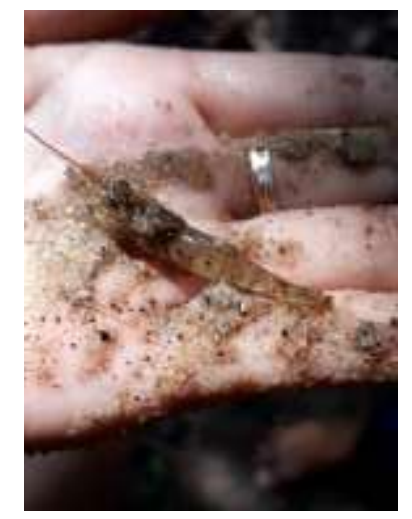

\section{Gambar 4. Udang Yang Dijumpai Di Air Terjun (Shrimp Found In The Waterfall)}

b. Ikan

Ikan adalah anggota vertebrata poikilotermik yang hidup di air dan bernapas dengan insang. Ikan merupakan kelompok vertebrata yang paling beranekaragam dengan jumlah spesies lebih dari 27.000 di seluruh dunia. Berbagai macam ikan yang ada di air terjun sebuak dan yang paling mudah untuk di jumpai adalah ikan badut (Amphiprioninae) dan ada juga ikan seluang (Rasbora), ikan kepuyu atau papuyu (Anabas testudineus), ikan sepat (Trichopodus trichopterus) dan jenis ikan lainnya.

\section{c. Primata}

Primata adalah mamalia yang menjadi anggota ordo biologi primates. Di dalam ordo ini termasuk lemur, tarsius, monyet, kera, dan juga manusia. Jenis primata yang ada di air terjun sebuak tidak begitu banyak karena primata di Kalimantan Barat itu sendiri sudah cukup banyak yang punah seperti orangutan, jenis yang ada di Air Terjun Sebuak yaitu kelempiau (Hylobates muelleri), dan monyet ekor panjang (Macaca fascicularis). Selain jenis primata ada juga fauna jenis makrofauna tanah seperti jangkrik (Gryllidae), kelabag tanah (Scolopendromorpha), serta jenis burung (Aves), kupu-kupu (Rhopalocera) dan ular (Serpentes).

\section{B. Potensi Non Hayati \\ 1. Fisik}

a. Air Terjun Sebuak

Air Terjun Sebuak merupakan salah satu Air Terjun yang ada di Kecamatan Nanga Tayap yang memiliki 4 tingkatan dan memiliki tinggi keseluruhan 90,3 m yang masing-masing mempunyai tinggi 22,5 m di setiap tinkatnya, Air Terjun Sebuak memiliki pandangan lepas untuk menikmati keindahan alam, suasana yang nyaman, udara yang sejuk dan suara gemuruh air yang ditimbulkan sehingga membuat para pengunjung tidak bosan untuk berkunjung. 


\section{b. Kolam atau lubuk}

Lubuk adalah bagian terdalam dari sungai, dapat pula berarti cekungan (dalam) didasar sungai. Aliran air di lubuk biasanya tenang atau bahkan relatif tidak mengalir. Air Terjun Sebuak memiliki kolam atau lubuk yang terbentuk secara alami dan memberikan daya tarik pada lokasi Air Terjun Sebuak itu sendiri yang berada dibawah aliran air terjunnya, biasanya kolam atau lubuk tersebut menjadi tempat para pengunjung untuk berenang.

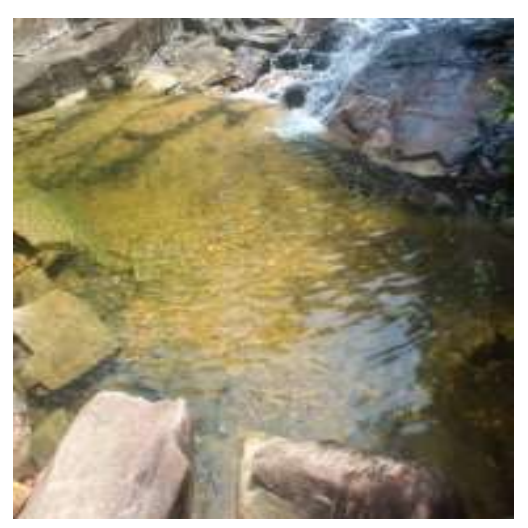

Gambar 5. Kolam Di Air Terjun Sebuak(Pool In Sebuak Waterfall)

c.

Menikmati Keindahan Alam.

Kegiatan menikmati keindahan sangat cocok dilakukan di Air Terjun Sebuak dengan panorama alam yang begitu indah serta beranekaragam jenisjenis tumbuhan yang masih asli, dan suara gemuruh Air Terjun yang jatuh serta melakukan kegiatan fotografi.
Keindahan alam dapat dilakukan dengan menikmati pandangan lepas dalam objek, pandangan lepas menuju objek, serta variasi pandangan dalam objek yaitu pemandangan pengunjung serta pemandangan alam yang indah di puncak Air Terjun Sebuak. 
Vol. 7 (2) : $668-681$

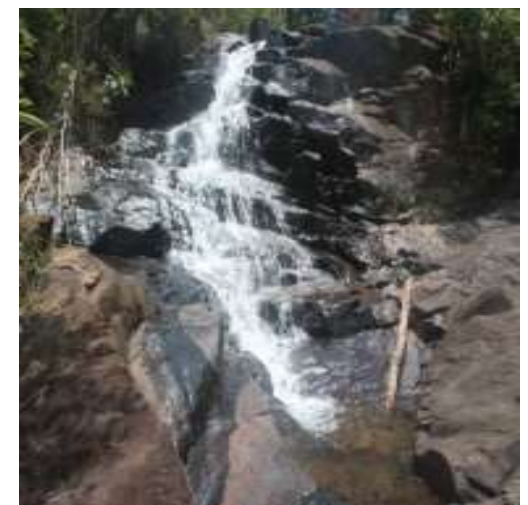

a

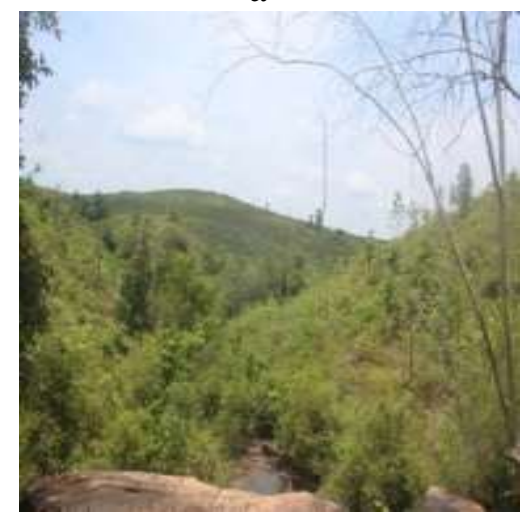

$\mathrm{c}$

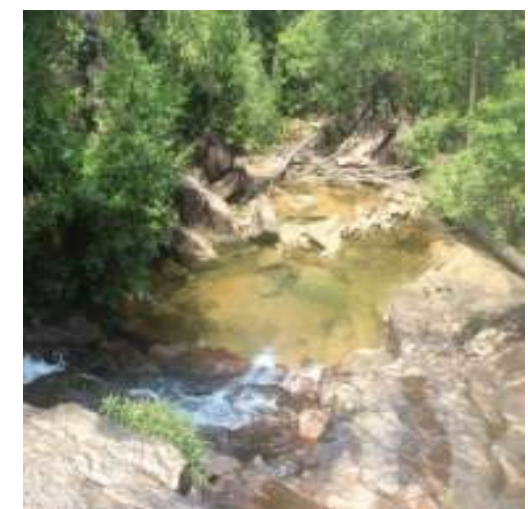

b

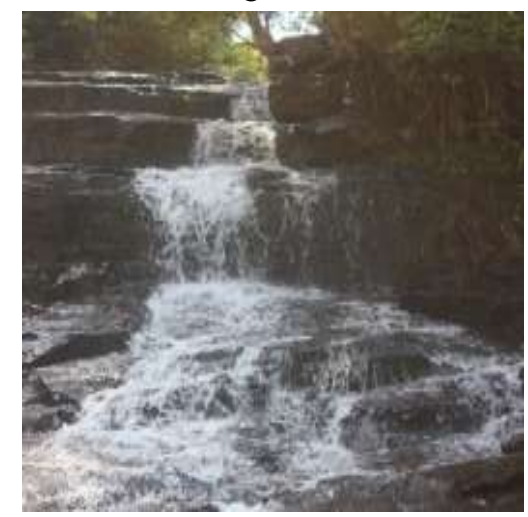

d

Gambar 6.KeindahanAlam Air TerjunSebuak

a. Kondisi di Atas Air Terjun Sebuak (ConditionOn Sebuak Waterfall)

b. Kondisi di Kaki Air Terjun Sebuak (Condition Under Sebuak Waterfall)

c. Pemandangan Lepas Menuju Air Terjun Sebuak (View Towards Sebuak Waterfall)

d. Variasi Kondisi Pandangan Dalam Air Terjun Sebuak (Variations On Condition Of View In Sebuak Waterfall)

Hamparan bukit-bukit yang indah nampak dari Air Terjun Sebuak, bukit yang terlihat merupakan bukit yang masih lebat ditumbuhi pepohonan yang sangat rimbun dan memiliki kerapatan yang masih alami, karena Air Terjun Sebuak masuk dalam kawasan hutan lindung.

Variasi pandangan dalam Air Terjun menggambarkan keindahan suatu air terjun baik itu debit air atau aliran air yang menunjukan air itu deras atau tidaknya, batuan yang beragam, dan tanaman yang ada disekitar Air Terjun. d. Geologi

Kawasan Air Terjun Sebuak banyak memiliki batuan besar dan cukup menonjol. Selain itu batuan tersebut dapat dilihat secara jelas oleh para pengunjung yang datang berkunjung, oleh sebab itu batuan merupakan sumber daya alam yang menonjol dikawasan tersebut. 


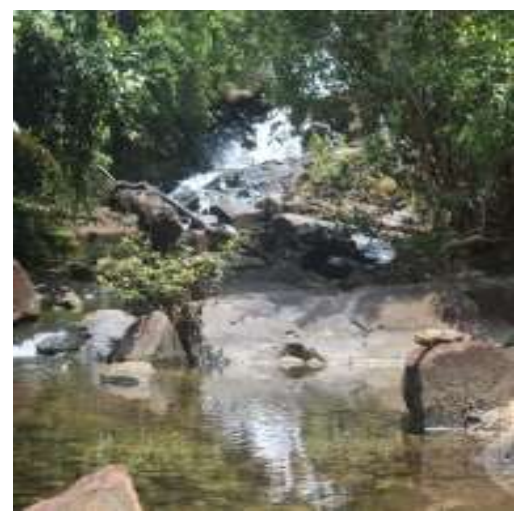

Gambar 7. Kondisi Bebatuan Yang Ada Di Air Terjun Sebuak (Rocks In Sebuak Waterfall)

e. Air

Air merupakan sumber daya alam yang mnonjol di lokasi Air Terjun Sebuak tersebut. Kondisi airnya juga bersih, biasanya masyarakat sekitar mengkonsumsi airnya secara langsung, namun jangan ditiru karena masingmasing orang memiliki kondisi tubuh yang berbeda. Para pengunjung tersebut berwisata sambil bermain air, bahkan mereka memancing untuk menu santapan siang.

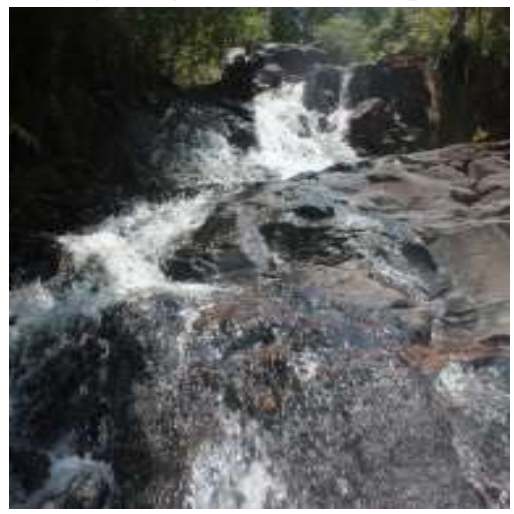

Gambar 8. Kondisi Air di Air Terjun Sebuak (Water In Sebuak Waterfall)

\section{Budaya}

Budaya merupakan suatu cara hidup yang berkembang, dan dimiliki bersama oleh sebuah kelompok orang, dan di wariskan dari generasi ke generasi. Budaya terbentuk dari banyak unsur yang rumit, termasuk sistem agama dan politik, adat istiadat, bahasa, perkakas, pakaian, bangunan, dan karya seni. Budaya yang ada di permukiman sekitar Air Terjun tidak begitu kuat karena masyarakat di Dusun Sebuak tidak ada adat tertentu untuk memperlakukan air terjun seperti memuja atau berdoa di sekitaran air terjun, masyarakat di Dusun Sebuak hanya menggunakan adat untuk upacara pernikahan dan lainnya.

\section{Pilihan Kegiatan Rekreasi}

Jenis kegiatan wisata alam merupakan kegiatan yang biasa dilakukan oleh pengunjung saat berada dikawasan wisata.

a. Kegiatan Memancing

Kegiatan memancing dapat dilakukan oleh para pengunjungyang datang 
berkunjung. Kondisi sungai yang mengalir di Air Terjun Sebuak merupakan spot memancing dengan beberapa jenis ikan, keanekaragaman jenis ikan maupun biota air lainnya dapat menjadi nilai tambah bagi para pemancing, jenis ikan yang biasa di dapatkan oleh pemancing adalah ikan sepat, kepuyu, seluang, bilis, dan ikan hias ikan botia atau sering disebut ikan badut selain melakukan kegiatan memancing pengunjung juga dimanjakan dengan pemandangan Air Terjun Sebuak yang tinggi dan sejuk.

b. Tracking ( pejalanan wisata )

Jalur tracking disekitar Air Terjun Sebuak masih memprihatinkan karena kurang memadai. Hal ini dapat dilihat dari kodisi jalannya yang belum baik, sempit dan licin. Untuk sampai kelokasi Air Terjun Sebuak pengunjung akan menaiki dan menuruni bukit yang banyak kerikil dan licin.

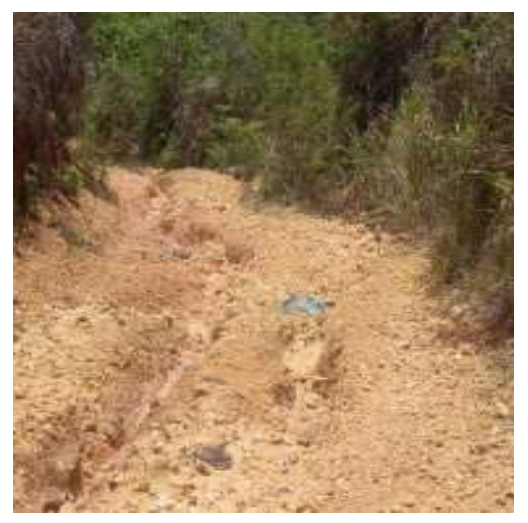

Gambar 9. Jalur Tracking Menuju Lokasi Air Terjun Sebuak (Tracking Path To The Location Of Sebuak Waterfall)

c. Kegiatan Berenang

Kegiatan berenang sangat menyenangkan untuk dilakukan sesampainya dilokasi Air Terjun Sebuak, apalagi setelah melakukan perjalanan yang cukup sulit, namun itu semua akan terbayarkan setelah pengunjung melihat Air Terjun Sebuak yang begitu menakjubkan. Saat melakukan kegiatan berenang pengunjung harus berhati-hati karena banyak batuan.

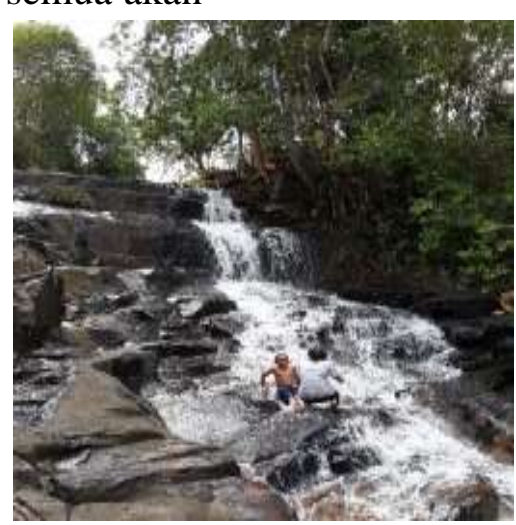

Gambar 10. Kegiatan Bermain Air di Air Terjun (Water Play Activities At The Waterfall) 
d. Berkemah

Kegiatan berkemah cukup bagus dilakukan dikawasan Air Terjun Sebuak, apalagi bagi para pengunjung yang mempunyai hobi berpetualang. Lokasi untuk berkemah diharapkan tidak terlalu dekat dengan air terjun, lokasi yang biasa digunakan untuk berkemah di Air Terjun Sebuak kini sudah banyak di tumbuhi tanaman dan rumput karena sudah lama sekali tidak ada yang berkemah di Air Terjun ini.

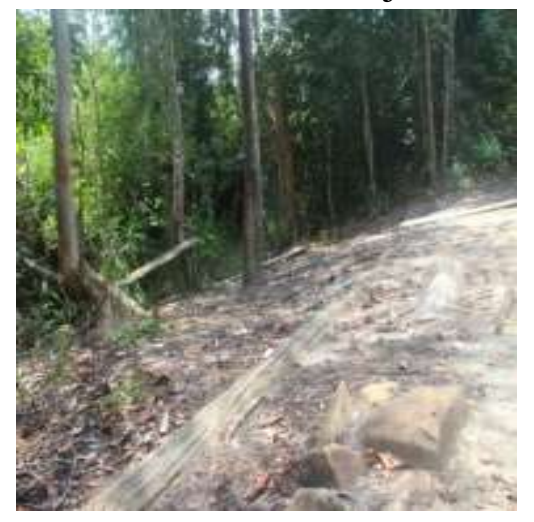

Gambar 11. Lokasi Berkemah (Camping Location)

\section{e. Kegiatan Pendidikan}

Lokasi Air Terjun Sebuak dapat menjadi tempat untuk menambah pengetahuan alam yang mana bisa dilakukan pelajar langsung berinteraksi dengan alam. Lokasi ini juga pernah dijadikan tempat penambahan ilmu bagi pencinta alam yang dilakukan oleh beberapa sekolah yang ada di Desa Nanga Tayap.

\section{Kebersihan Udara dan Lokasi}

Kebersihan udara dan lokasi di kawasan Air Terjun Sebuak merupakan salah satu faktor yang dapat menarik minat para pengunjung untuk datang mengunjungi lokasi tersebut. Apabila lokasinya tidak bersih dan udaranya tercemar maka akan mengurangi keinginan pengunjung untuk datang berkunjung.

a. Pemukiman Penduduk

Jarak pemukiman dengan lokasi Air Terjun Sebuak cukup jauh sekitaran 3-4 $\mathrm{km}$ dari pemukiman, jadi tidak mengganggu kebersihan udara dan lingkungan di kawasan Air Terjun tersebut. 


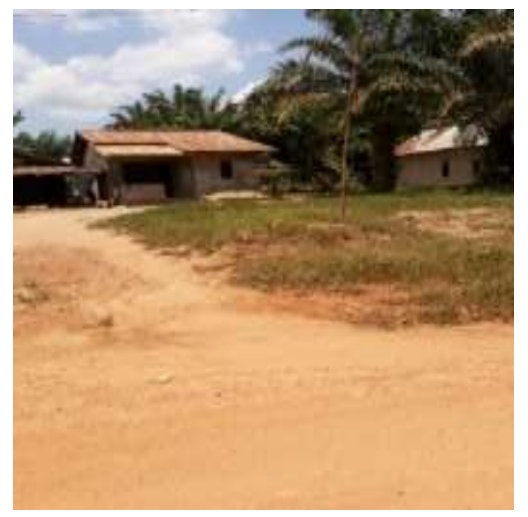

\section{b. Sampah}

Kawasan Air Terjun Sebuak tidak ada sampah yang mengganggu, karena sampah hanya dari dedaun yang berguguran dan kayu-kayu yang sudah rapuh akibat air. Jadi sampah tidak mengganggu pemandangan para pengunjung saat menikmati panorama alam sekitar Air Terjun Sebuak.

c. Binatang

Keberadaan binatang dikawasan Air Terjun Sebuak tidak mengganggu kebersihan udara dan lingkungan, karena pemukiman cukup jauh dari lokasi tersebut. Pengunjung juga tidak tertanggu saat bersantai dan menikmati pamandangan disekitar kawasan tersebut.

d. Jalan Ramai
Lokasi Air Terjun Sebuak bebas dari jalan ramai karena lokasinya agak masuk kedalam jadi tidak mengganggu kebersihan udara dan lingkunga disekitarnya, karena tidak adanya jalan ramai maka tidak ada kendaraan yang melintas kawasan tersebut sehingga tidak ada polusi yang dapat mengganggu kebersihan udara dilokasi tersebut.

e. Coret-coretan

Kawasan Air Terjun Sebuak terdapat sedikit coret-coretan yang sedikit mengganggu pemandangan para pengunjung. Kepada pengunjung yang ingin berkunjung di kawasan air terjun diharapkan tidak mencoret-coret batu maupun pohon yang ada dikawasan tersebut agar pengunjung yang lain dapat menikmati pemandangan yang indah. 

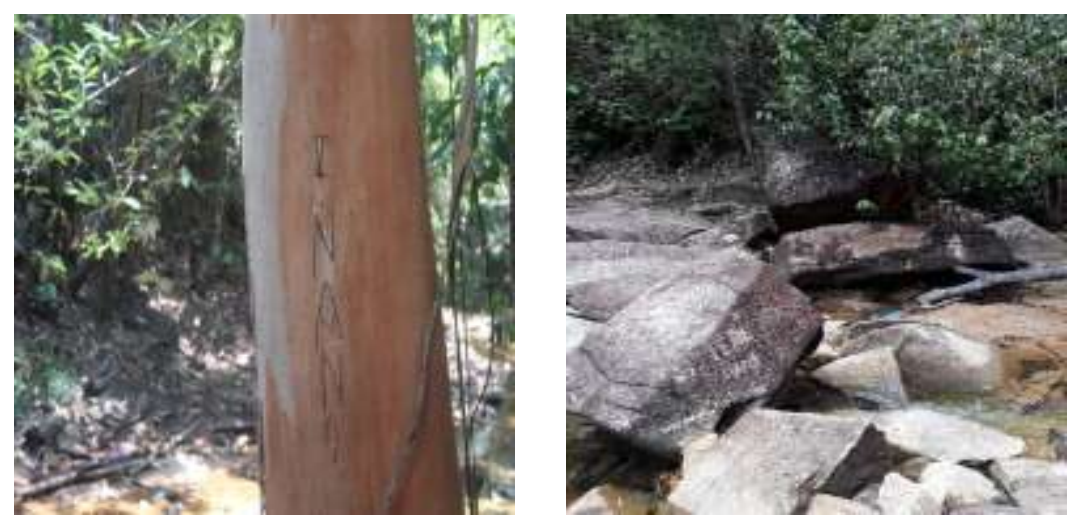

Gambar 13. Vandalisme Yang Ada Di Pohon dan Batu Di Air Terjun Sebuak(Vandalism In Trees and Stones in Sebuak Waterfall)

\section{f. Industri}

Kawasan Air Terjun Sebuak bebas dari kegiatan industr, sehingga tidak mengganggu kebersihan udara dan lingkungan. Meskipun tidak ada industri namun perkebunan kelapa sawit yang tidak jauh dari lokasi air terjun sangat memprihatinkan, sehingga sangat diharapkan kepada para perangkat desa dan pemerintah setempat untuk menjaga kelestarian hutan dikawasan air terjun tersebut.

\section{E. Keamanan}

Keamanan merupakan faktor yang paling penting bagi para pengunjung yang datang. Tanpa adanya rasa aman yang tercipta, maka akan mengganggu para pengunjung yang datang, sehingga pengunjung tidak menikmati waktunya dilokasi tersebut.

Informasi dan wawancara dari masyarakat yang mengetahui air terjun tersebut kawasan Air Terjun Sebuak secara religius tidak ada kepercayaan yang mengganggu, sedangkan dari sudut padang non religius masih ada yang percaya dengan tidak diprbolehkannya berkata-kata kasar dan jorok.

\section{F. Kenyamanan}

Rasa nyaman di lokasi wisata akan menambah minat pengunjung untuk mengunjungi kembali lokasi tersebut. Berdasarkan hasil wawancara dengan pengunjung menunjukan bahwa kawasan Air Terjun Sebuak merupakan kawasan yang sangat nyaman karena bebas dari bau yang mengganggu, tidak ada lalu lintas kendaraan yang mengganggu, bebas dari kebisingan dan memiliki udara yang sejuk dan bersih. Untuk pelayanan terhadap pengunjung masih kurang karena belum ada struktur kepengelolaan di kawasan Air Terjun Sebuak tersebut.

\section{G. Kondisi Lingkungan Sosial Ekonomi}

Penilaian kriteria kondisi lingkungan sosial ekonomi diperlukan karena sangat penting dalam mendukung potensi pasar. Penilaian kriteria kondisi lingkungan sosial ekonomi dinilai dalam radius $5 \mathrm{Km}$ dari batas kawasan insentive use atau jarak terdekat dalam objek. Unsur-unsur yang dinilai adalah tata ruang wilayah objek, status lahan, mata pencaharian, penduduk dan tingkat pendidikan.

\section{H. Sarana Prasarana Penunjang}

Sarana-prasarana penunjang merupakan salah satu faktor yang dapat menunjang kemudahan dan kenyaman bagi 
pengunjung dalam kegiatan wisata. Sarana penunjang meliputi rumah makan, pusat perbelanjaan/ pasar, Bank, toko souvenir/ cinderamata dan angkutan umum. Sarana prasarana penunjang yang terdapat di lokasi Air Terjun Sebuak sangat kurang dikarenakan Air Terjun Sebuak belum ada yang mengelola sehingga pengunjung harus memenuhi kebutuhannya sendiri kecuali di hari raya biasanya masyarakat sekitar membuka lapak kecil-kecilan.

\section{Ketersediaan Air Bersih}

Air bersih merupakan faktor yang harus tersedia dalam pengembangan suatu tempat wisata baik untuk pengelolaan maupun pelayanan. Untuk kelayakan konsumsi umumnya air yang ada di Air Terjun Sebuak dapat dikonsumsi namun dibutuhkan perlakuan sederhana yaitu harus di saring dan dimasak dahulu dan selalu tersedia sepanjang tahun meskipun saat kemarau.

\section{Kesimpulan}

Berdasarkan hasil penelitian Identifikasi Potensi Air Terjun Sebuak maka dapat disimpulkan antara lain:

1. Potensi hayati yang ada di Air Terjun Sebuak adalah berbagai macam flora yang menarik seperti pohon cemara, rotan, jenis tumbuhan ekaliptus, jenis jamur, tanaman hias seperti palempaleman, pandan, pucuk merah, kantong semar dan lainnya, dan terdapat beberapa macam jenis fauna seperti udang, jenis ikan air tawar seperti papuyu, sepat, badut, dan seluang, dan beberapa jenis primata seperti kelempiau dan monyet ekor panjang, beberapa mikrofauna tanah seperti kelabang, ulat kaki seribu, jenis brung, belalang serta ular.

2. Potensi non hayati yang ada di Air Terjun Sebuak meliputi fisik seperti Air Terjun Sebuak itu sendiri, kolam, keindahan alam, geologi, kebersihan air, dan budaya yang ada di sekitaran Air Terjun Sebuak.

3. Kegiatan yang dapat dilakukan di Air Terjun Sebuak antara lain menikmati keindahan, memancing, tracking, berkemah, pendidikan maupun penelitian yang didapat dari Air Terjun Sebuak ini.

Jadi dapat disimpulkan bahwa kawasan Air Terjun Sebuak memiliki potensi daya tarik yang bisa dikembangkan sebagai tempat wisata alam, namun masih banyak yang harus dibenahi seperti aksesibilitas di perbaiki dan dipermudah, akomodasi seperti penginapan harus tersedia, sarana prasarana penunjang harus dibangun didekat lokasi, namun harus memperhatikan aturan yang berlaku, dan harus adanya kerjasama yang interaktif antara pemerintah, masyarakat, dan pihak swasta/ investor.

\section{Saran}

1. Upaya yang harus dilakukan agar Air Terjun Sebuak dapat dikembangkan menjadi daerah wisata perlu adanya investor atau kebijakan dari dinas terkait.

2. Perlu peningkatan sarana dan prasarana penunjang sehingga pengembangan pariwisata di Air Terjun Sebuak akan lebih baik lagi.

3. Perlu adanya dukungan masyarakat dan pemerintah setempat dalam upaya 
perbaikan dan pengembangan pariwisata di Air Terjun Sebuak.

\section{DAFTAR PUSTAKA}

Fahrian HH, Putro SP, Muhammad F. 2015. Potensi Ekowisata di Kawasan Mangrove Desa Mororejo Kabupaten Kendal. Biosaintifika 7(2): 105-111.

Hakim L. 2004. Dasar-Dasar Ekowisata. Bayumedia Publishing, Malang.

Marpaung, H. 2002. Pengetahuan Kepariwisataan Edisi Revisi. Bandung: Alfa Beta.
Soekadijo. R. G. 2000. Anatomi Pariwisata Memahami Parawista Sebagai System Linkage. Jakarta: PT. Gramedia Pustaka Utama.

Sugiyono. 2010. Metode Penelitian Pendidikan Pendekatan Kuantitatif, Kualitatif dan R \& D. Bandung : Afabeta.

Undang-Undang Nomor. 5. 1990. Tentang Konservasi Sumber Daya Alam Hayati dan Ekosistemnya. Jakarta. 